\title{
Design and numerical simulation of the heat exchanger for heat recovery system with melting furnaces for melting secondary aluminums
}

\author{
S. Gavlas ${ }^{1 \mathrm{a}}$, R. Lenhard ${ }^{1}$, and J. Jandačka ${ }^{1}$ \\ ${ }^{1}$ University of Žilina, Faculty of Mechanical Engineering, Department of Power Engineering, Univerzitna 1, \\ 01026 Žilina, Slovakia
}

\begin{abstract}
Many industrial technology equipment produces residual (waste) heat. This heat in the form of combustion allows the use of enthalpy drop for heat recovery and can be used to power other devices, which may partially or completely replace the fuel or energy. Significant limiting factor in the construction of systems for heat recovery, however, dust flue contained in flue gas, which adhere to the heat transfer surface area, and when the impossibility of cleaning them often lead to malfunctioning of these devices. This article offers the possibility to use this energy through regenerative devices.
\end{abstract}

\section{Introduction}

In industrial technologies are often the massive flows of low and medium waste heat potential. This source of heat is advantageous in the utilization of appropriate equipment back to use as a secondary energy resources in the best technologies that produce it. Secondary energy sources generally arise as a result of fuel and energy consumption in technological processes, which do not, however, because their parameters are unsuitable for the original technology. This may be a source of energy for other devices, which can completely or partially replace fuel or energy. One way to reduce the cost of thermal energy is the recovery of waste heat through heat exchangers of various structures, depending on the application. The whole device was modeled using Pro / ENGINEER. It is a system that covers the entire development process, from conceptual design through simulation, to manufacturing. Parameterization is based on structural features and its full associativity. It was created with a number of drawings of drawings about 540 pieces, which serves to complete the entire device manufacturability. The following chapters will be given the great breadth of the problem only briefly described the various structural elements.

\section{Melting aggregate}

Thermal aggregate is the melting furnace figure 1 heated by gas burners. The furnace is the type of chamber. This is achieved in two ways mechanically by inserting aluminum and solid waste mixture through openable doors located in front of the furnace or pouring through the hole located on the side of the furnace above the molten metal. Pouring hole performs a dual function (pour in liquid metal into a furnace from another remelt furnaces and pouring molten metal into the transport channels, which transport metal into another furnace). The furnace is rotated around the axis of pins, and during the working cycle leads to the deflection by $30^{\circ}$. The furnace is equipped with a gas burner that regulates flame above the surface of the melt. Flue gases are discharged through the chimney to the hood and are subsequently mixed in the cold air to reduce the temperature for operating the filter.

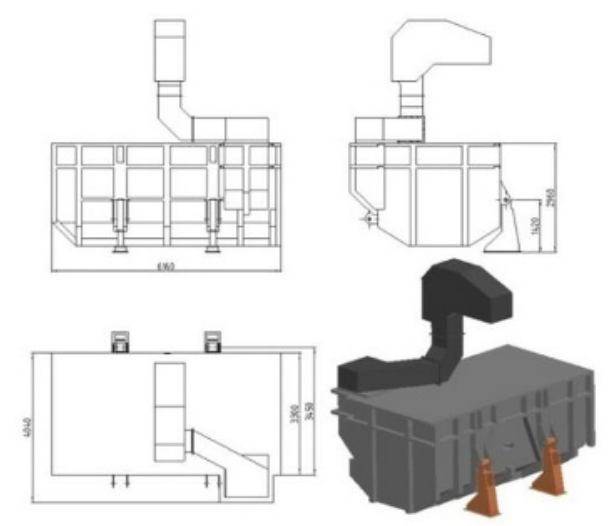

Fig. 1. 3D model of the melting aggregate and its $2 \mathrm{D}$ views.

Given the harsh environment and a large gas stickiness cannot use standard commercially available heat exchangers.

It is therefore necessary to design heat exchangers with respect to these specific requirements:

- To ensure easy and efficient cleaning of heat transfer surface area of gas deposits.

astanislav.gavlas@fstroj.uniza.sk 
- To adapt the design simple exchangeability and especially the parts that come into contact with the flue and are likely to lower corrosion resistance material.

- Take into account the tilting furnace.

- Respect the layout options furnace itself and the surrounding areas and equipment in the production hall.

Based on available information suggested the gradual recuperation device consisting of two main functional parts:

- System exchangers: combustion products - air.

- Exchange system heat flue: combustion products water.

\section{Heat exchange equipment combustion products - air}

Its main function is to ensure that flue gases from the melting unit and subsequently transported to the second heat transfer device combustion products - water. It also serves to preheat the hot air that is blown into the burner, using just the heat from the flue gas. The heat pipe system is used, which are provided with a steel cover. This creates space around the flue pipe, which is forced through the upstream gas flow cold air supplied from the fan. Given unstableness furnace was necessary to insert a tube circuit heat exchange surfaces swivel mechanism, respectively swivel. It is located on the axis of rotation pivots. At the same time swivel system divided into two heat exchangers. One part is fixed placed on the oven and tilt with it, while the second is placed on stands, which are tightly linked to the ground. In the bending duct systems are installed in the knees. They serve as inspection, respectively cleaning holes.

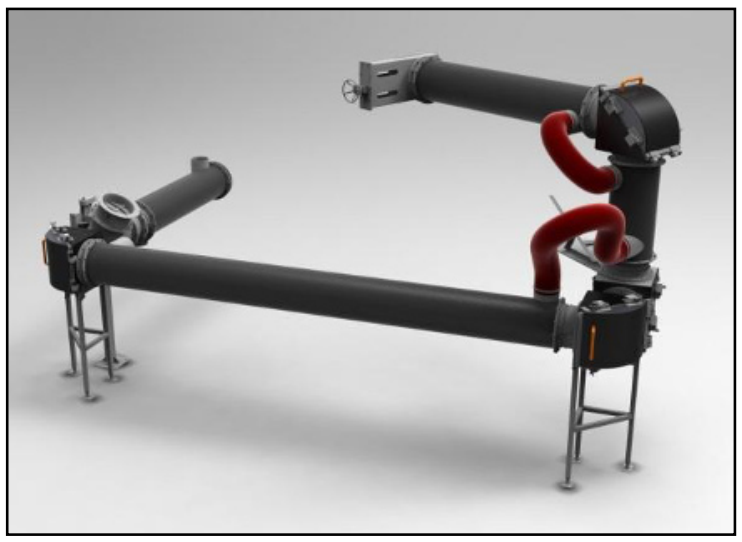

Fig. 2. Exchanger combustion - air.

During the design of heat exchangers, either combustion products - air or combustion products - water to create fundamentally more functional solutions. In figure 2 shows the final version.

The proposed structure consists of these basic functional elements:

- Shut-off valve.

- 4 hot air, respectively exchangers.

- 4 bends with inspection openings.

- Swivel.

- T-bend.

- 2 shut-off valve with automatic control.

- support (Help) structure.
Table 1. Basic design characteristics of the exchanger.

\begin{tabular}{|c|c|c|}
\hline Parameter & Unit & Value \\
\hline $\begin{array}{c}\text { Flue gas } \\
\text { ducts pipe } \\
\text { total length) }\end{array}$ & $\mathrm{mm}$ & $\begin{array}{c}\text { Tr. Ø } 406 \times 10- \\
12000\end{array}$ \\
\hline $\begin{array}{c}\text { Air heating } \\
\text { pipe (total } \\
\text { length) }\end{array}$ & $\mathrm{mm}$ & $\begin{array}{c}\text { Tr. Ø } 460 \times 4- \\
11000\end{array}$ \\
\hline $\begin{array}{c}\text { Operating } \\
\text { temperature } \\
\text { combustion }\end{array}$ & ${ }^{\circ} \mathrm{C}$ & $600-900$ \\
\hline $\begin{array}{c}\text { Operating } \\
\text { temperature } \\
\text { of the air }\end{array}$ & ${ }^{\circ} \mathrm{C}$ & $0-250$ \\
\hline $\begin{array}{c}\text { Internal } \\
\text { volume of } \\
\text { flue gas } \\
\text { ducts }\end{array}$ & $\mathrm{m}^{3}$ & 1.6 \\
\hline $\begin{array}{c}\text { Internal } \\
\text { volume of } \\
\text { air heaters }\end{array}$ & $\mathrm{m}$ & 3480 \\
\hline $\begin{array}{c}\text { Heat } \\
\text { exchange } \\
\text { surface } \\
\text { combustion } \\
\text { - air }\end{array}$ & $\mathrm{Pa}$ & 14 \\
\hline $\begin{array}{c}\text { Mass } \\
\text { exchanger }\end{array}$ & $\mathrm{kg}$ & 3500 \\
\hline $\begin{array}{c}\text { Max. Static } \\
\text { pressure fan } \\
\text { air }\end{array}$ & $\mathrm{m}^{2}$ & 0.45 \\
\hline
\end{tabular}

\section{Heat exchange equipment combustion products - water}

It is used for hot water. This is a closed water circuit. It consists of a vertical flue gas chamber in which are placed horizontally field - pipe, in which heated water flows. Gas flow direction is upwards. Field - pipes are due to assembly and disassembly is divided into segments, allowing for easy replacement of the disorder. Flue gas chamber is accessible from three side's openable doors, allowing easy and efficient cleaning. Gas and water flow is controlled by valves, slider and valves which are controlled by an automatic control system. If necessary, they can be drive manually.

Combustion products entering the exchanger manually sealable flap continue a metal diffuser tubes exchanger pass area, continuing a metal concentrator flow through manually closeable flap in the chimney. Gas flow direction is upwards. The main functional part of the heat exchanger is field - tube. It's a tube in a tube, a space segment of the inner tube water flows to the end of the tube, where the current reverses and water flows back into the second annular cross-sectional area of the segment. Field - tubes with functional spaces for the flow of gas filled the entire cross section of flue gas ducts. Combustion products flow perpendicular (transverse) to the tube. The entire heat exchanger is inclined $3^{\circ}$, because of breathing field-tubes when filling the system with water. The tubes are arranged in groups. Segments are interconnected tubes so that the flowing water from 
entering the heat exchanger flows in two branches parallel to the output of the heat exchanger.

Table 2. Basic design characteristics of the exchanger.

\begin{tabular}{|c|c|c|}
\hline Parameter & Unit & Value \\
\hline $\begin{array}{c}\text { Field - pipe } \\
\text { external } \\
\text { dimension }\end{array}$ & $\mathrm{mm}$ & $\varnothing 60.3$ \\
\hline $\begin{array}{c}\text { Number of } \\
\text { segments }\end{array}$ & piece & 28 \\
\hline $\begin{array}{c}\text { Number of } \\
\text { tubes in the } \\
\text { segment }\end{array}$ & piece & 280 \\
\hline $\begin{array}{c}\text { Total } \\
\text { number of } \\
\text { tubes }\end{array}$ & piece & max. 600 \\
\hline $\begin{array}{c}\text { Operating } \\
\text { temperature } \\
\text { combustion }\end{array}$ & ${ }^{\circ} \mathrm{C}$ & $90 / 70$ \\
\hline $\begin{array}{c}\text { Operating } \\
\text { temperature } \\
\text { combustion }\end{array}$ & ${ }^{\circ} \mathrm{C}$ & \\
\hline \multicolumn{2}{|l}{}
\end{tabular}

Segments figure 3 are fixed with screws in the frame that the walls are three openable 4 - exhaust multifaceted. The fourth wall segments are mounted one above the other. For reasons of tightness and also to protect the interconnecting tubing segments are segments covered with a removable cover. Gaps between segments are tight-glue or other suitable soft seal. If the segments are still leaks, the area under the cover is sucked up the chimney pipe. Openable walls are welded from sheet metal, hung on hinges and locked in the closed position by screw caps. Are tight - liners. In the lower area of the cleaning combustion entry hole is of similar construction as the vertical walls. Interior surfaces of walls, base area segments, input and output are provided with $30 \mathrm{~mm}$ thick fireproof ceramic insulating layers. Exchanger is the steel structure of rolled profiles. As part of this structure is slatted platform designed for service and cleaning field - pipes exchanger. The structure is anchored to the floor with screws.

\section{Numerical simulation of the segment of field's pipe}

Numerical models figure 3 were developed on the basis of a real model of fields' pipe designed.

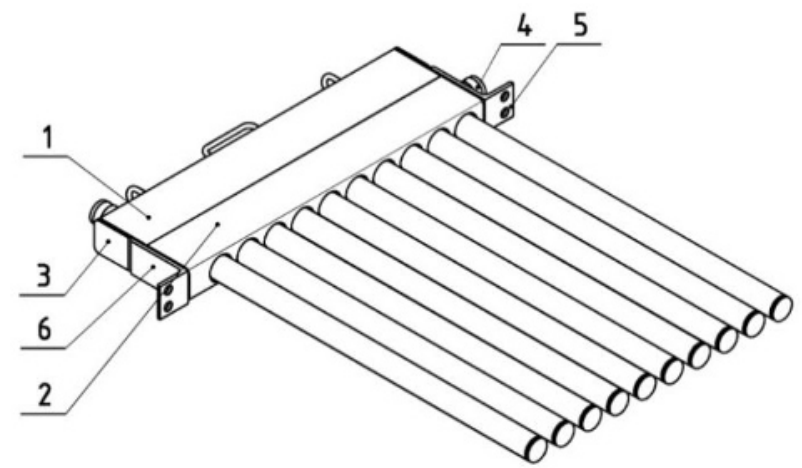

Fig. 3. Segment of fields' pipe.
To verify the accuracy of engineering design analysis was carried using simulation software, FLUENT. As the basis for this analysis has served 3D model designed equipment, which files have been transferred to step format.

After meshed has been given as a model for boundary zones (where geometry is fluid, solid and where is an input and an output). Fluent program is commonly used CFD software, which defines boundary conditions that are understood as a precondition for the correct calculation. The Turbulent model was as two - equations $\mathrm{k}-\varepsilon$. This is the most widely tested and used a twoequation -transport- model (two transport equations for $\mathrm{k}$ and $\varepsilon$ ). The $\mathrm{k}-\varepsilon$ model generally gives good results in simple flows as far as the means of the velocities and energies are concerned. But it cannot predict sufficiently the specific characteristics of complex flows (a recirculation of the regions, the secondary flows, etc.).

Simulations were conducted for the following input conditions:

- Heating temperature.

- Medium and ambient temperature.

- Wall temperature at the pipe.

- Shell conduction for intakes heat to the water.

Results from numerical simulation:

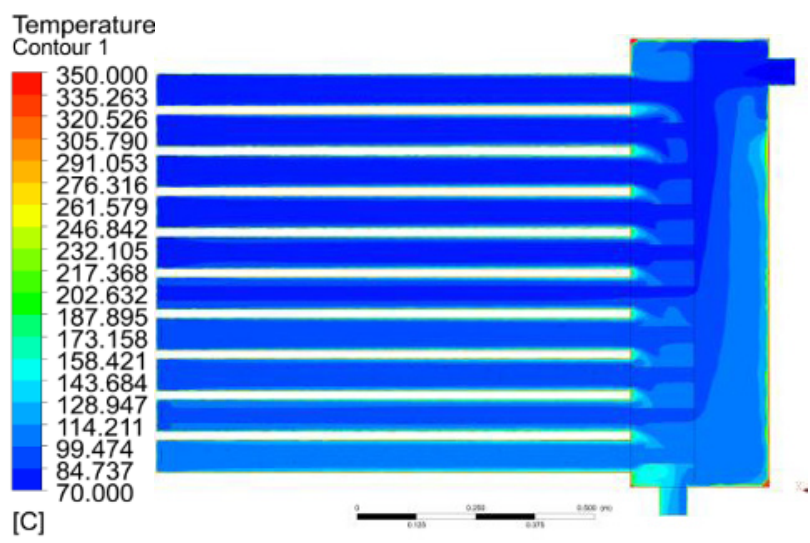

Fig. 4. Average wall temperature.

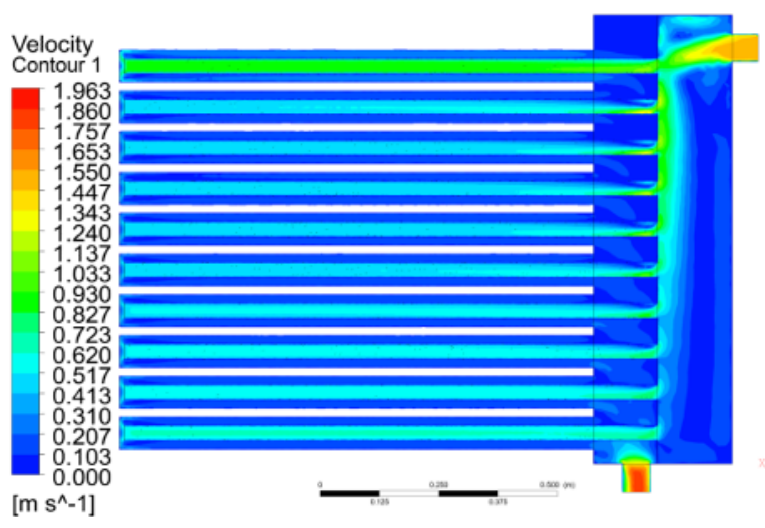

Fig. 5. The isotach flowing medium.

In figure 4 and figure 5 are shows contour of temperature and isotachs (contours of velocity) flowing gas passing through the cooled flue gas field's pipe heat exchanger. The cut is made the axis heat exchanger so as 
to best see the distribution of medium velocity in the pipe. The purpose of this simulation was to create a numerical model to handle by which it will be possible to analyze whole device.

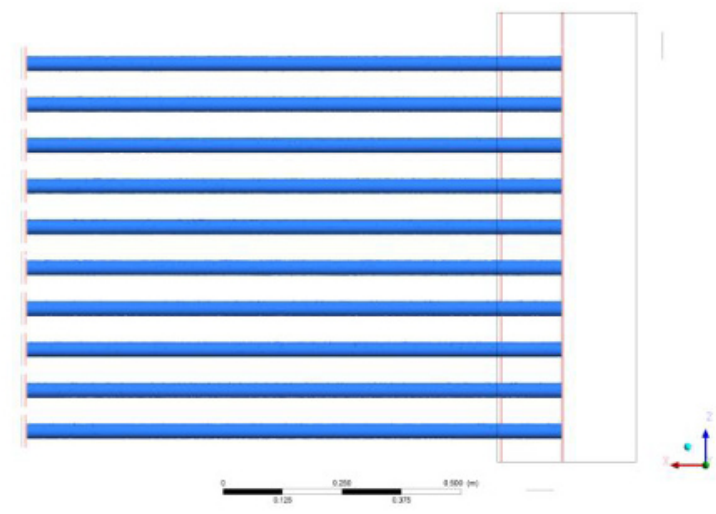

Fig. 6. Position of line where was get results.

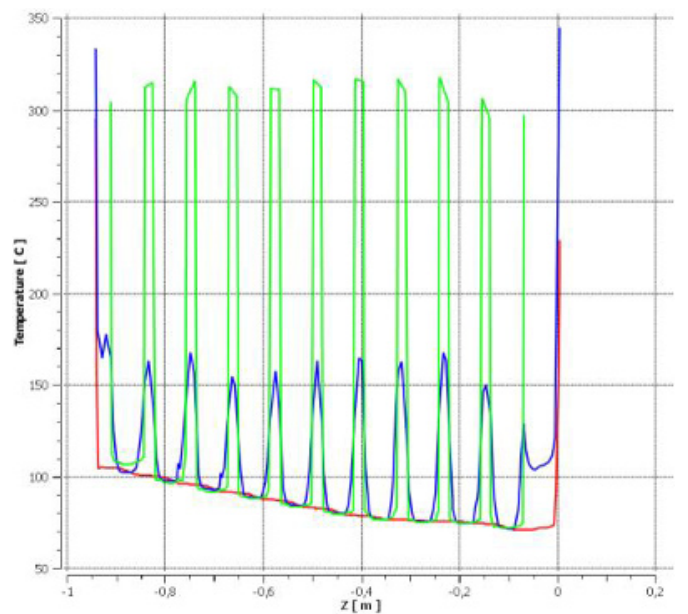

Fig. 7. Result of medium temperature flow through the heat exchanger.

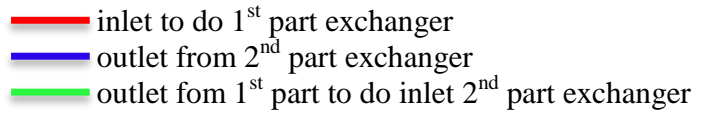

In figure 7 can we see result of temperature in the 3 positions which is shown in figure 6 and figure 7 show how effective this field's heat exchanger working.

\section{Conclusion}

The result is a regenerative device that was designed complete. It is composed of two basic functional units of the heat exchanger and combustion - combustion air heat exchanger - water. In both cases, the recovered heat source of combustion, deriving from the melting unit remelt furnace. Exchanger installed in the first order, is used to preheat the cold air that is pumped into the system piping gas burner, and its temperature can exceed $250{ }^{\circ} \mathrm{C}$. Then wander into the second exhaust gas heat exchanger where residual heat is used for hot water.

These contributions describe constructions design the involvement of the heat exchanger creation of CFD model and CFD simulation results of the field's heat exchanger. The results of CFD simulations can be said that the CFD simulation was managed. Based on the management of CFD Simulations field's exchanger can proceed to an overall analysis of the whole device using CFD methods.

\section{Acknowledgement}

This paper was prepared within the project VEGA no. $1 / 1290 / 12$.

\section{References}

1. S. Gavlas, Dizertačná práca, (ŽU v Žiline, 2010)

2. M. Malcho, S. Gavlas, R. Lenhard, Acta metallurgica Slovaca 2, 132-137 (2011)

3. R. Lenhard, M. Malcho, Elsevier-An International Journal Mathematical and Computer Modelling 57, 111-125 (2013)

4. B. Brienza, J. Gandy, L. Lackenbach, Heat exchanger design handbook, (HPC. USA, 1983)

5. J. Mikielewic, W. Nowak, Heat transfer and renewable sources of energy 1, 823 (2004)

6. R. Shar, D. Sekulč, Fundamentals of heat exchanger design (2003)

7. M. Vantúch, M. Jakubský, M. Malcho, TRANSCOM 9, 221-224 (2011) 